\title{
Malaria Zoonoses and its Future Challenges
}

\section{Saber Gholizadeh*}

Medical Entomology Department, School of Public Health, Urmia University of Medical Sciences, Urmia, Iran

After discovery of malaria parasites and their transmission by Anophelines, until recently, malaria was antroponotic disease caused by four Plasmodium species. These parasites were circulated among humans by different vectors around the world. Coatney [1] reported the first known case of naturally infected simian malaria, Plasmodium knowlesi, in human $[1,2]$. Near to half of century later that discovery, with applying molecular techniques, detection and identification of simian malaria, especially P. knowlesi, was renewed [3]. Recently, Baird [4] revised the biology and medicine of zoonoses malaria [4]. CoxSingh [5] indicated the role of other simian malaria, P. inui and P. synomology, in human infection at Southeast Asia [5].

It is clear that epidemiologic pattern of malaria is going to be changed to both anthroponotic and zoonoses. In this case there were many gaps which should have been filled. They are including the risk of $P$. knowlesi and other simian malaria, the prevalence of these parasite among macaque hosts, human to human transmission of theses parasites, mix infection of anthroponotic and zoonoses parasites.
This new epidemiologic picture of malaria reveals that previously diagnosis and control methods should have been revised and the elimination program of malaria would have essential challenges.

\section{References}

1. Coatney GR (1971) "The simian malarias: zoonoses, anthroponoses, or both?" Am J Trop Med Hyg 20: 795-803.

2. Townell N, Looke D, McDougall D, McCarthy JS (2012) "Relapse of imported Plasmodium vivax malaria is related to primaquine dose: a retrospective study." Malar J 11: 214.

3. Singh B, Kim Sung L, Matusop A, Radhakrishnan A, Shamsul SS, et al. (2004) "A large focus of naturally acquired Plasmodium knowlesi infections in human beings." Lancet 363: 1017-1024.

4. Baird JK (2009) "Malaria zoonoses." Travel Med Infect Dis 7: 269-277.

5. Cox-Singh J (2012) "Zoonotic malaria: Plasmodium knowlesi, an emerging pathogen". Curr Opin Infect Dis 25: 530-536.
*Corresponding author: Saber Gholizadeh, Medical Entomology Department School of Public Health, Urmia University of Medical Sciences, Urmia, Iran, E-mail: sabergholizadeh@yahoo.com, saber@umsu.ac.ir

Received December 01, 2012; Accepted December 05, 2012; Published December 10, 2012

Citation: Gholizadeh S (2013) Malaria Zoonoses and its Future Challenges. J Bacteriol Parasitol 3:e117. doi:10.4172/2155-9597.1000e117

Copyright: @ 2013 Gholizadeh S. This is an open-access article distributed under the terms of the Creative Commons Attribution License, which permits unrestricted use, distribution, and reproduction in any medium, provided the original author and source are credited. 